\title{
CORRENTES TEÓRICAS DO SÉCULO XX E AS DIFICULDADES DE EFETIVAÇÃO DA JUSTIÇA SOCIAL NO BRASIL
}

\author{
THEORETICAL CURRENCIES OF THE 20TH CENTURY AND THE \\ DIFFICULTIES OF THE EFFECTIVENESS OF SOCIAL JUSTICE IN BRAZIL \\ Lara Denise Góes da Costa ${ }^{1}$
}

\begin{abstract}
RESUMO: Este artigo visa dispor de algumas correntes teóricas do século XIX que se preocuparam em compreender as dificuldades de efetivação da justiça social. Primeiramente analisarei as teorias descritivo-normativas e posteriormente verificarei como os intérpretes brasileiros trouxeram a discussão teórica para as reivindicações de igualdade no Brasil. Assim podemos compreender como se desenvolveu a trajetória da cidadania no Brasil e ressaltar que embora tenhamos conseguido alcançar, entre altos e baixos, um sistema democrático de igualdade de direitos, sua efetivação de forma mais abrangente ainda não se efetivou em sua integralidade.
\end{abstract}

Palavras-chaves: cidadania, justiça, teoria

\begin{abstract}
This article aims at having some theoretical currents of the nineteenth century that were concerned with understanding the difficulties of effective social justice. Firstly, I will analyze the descriptive-normative theories and later I will verify how the Brazilian interpreters brought the theoretical discussion to the claims of equality in Brazil. Thus we can understand how the trajectory of citizenship in Brazil has developed and emphasize that although we have been able to reach a democratic system of equality of rights between highs and lows, its effectiveness in a more comprehensive way has not yet been fully realized.
\end{abstract}

Keywords: citizenship, justice, theory

O desenvolvimento das sociedades modernas cristalizou dois núcleos sistemáticos, a empresa capitalista e o aparelho burocrático do Estado, que juntos, traduziram uma ação econômica como meio para se atingir o desenvolvimento e a modernização social (Habermas; 2000). Este passa a ser o conceito de referência para a compreensão dos processos de formação do capital, poder político centralizado, produtividade do trabalho, expansão da vida urbana e da secularização de valores e normas. A partir do século XVII, a filosofia política européia tentará dar conta da emergência da idéia de Estado-nação e de cidade, sugerindo múltiplas hipóteses para a existência de um poder legítimo que reflita o interesse de todos e garanta a segurança e a paz. De Hobbes $(1992)^{2}$ e sua perspectiva individualista e egoística de ser humano à

\footnotetext{
${ }^{1}$ Pós-Doutora em Direitos Humanos pelo PNPD/Capes do Programa de Pós-graduação em Direito e evolução social da Universidade Estácio de Sá. Doutora em Filosofia pela UFRJ. Doutora em Ciências Sociais pela PucRio. Professora Colaboradora do Programa de Pós-graduação em Direito e evolução social da Universidade Estácio de Sá. Email: larinhas@ @otmail.com

${ }^{2}$ Cf. Hobbes, T. "Leviathan" e "Do cidadão." No primeiro, Hobbes desenvolve os fundamentos do estado de natureza e do contrato hipotético com vistas à manutenção da ordem política. No segundo, Hobbes desenvolve a idéia que fundamenta a construção da cidade como resultado da soma de interesses e como a segurança interna é
} 
pacificidade e ingenuidade do homem Rousseauniano ${ }^{3}$ do século XVIII, a modernidade trouxe consigo uma nova idéia de ser humano baseada no convívio concreto da realidade e convivência social. A preocupação com a segurança e com as normas sociais até então tinham como base a fundamentação da igualdade num sentido formal, apenas numa conotação de humanidade abstrata. Com a virada epistemológica marxista no século XIX, a igualdade será entendida sob o viés materialista da história, de forma a dar conta dos processos de subjugação social de ser humano a ser humano através da ordem econômica e do trabalho ${ }^{4}$.

No entanto, é também a partir do século XX que "a questão social” como questão de Estado surge como crise do Estado-providência. Para Rosanvallon (1998), há três tipos de crise que caracterizaram a problemática da construção do Estado e suas disfunções no contexto da sociedade industrial: A primeira crise é a financeira, na qual a mão invisível Smithiana não favorece as demandas por melhores condições socioeconômicas e trabalhistas. A segunda é ideológica do próprio Estado, na qual o vínculo estatal com o indivíduo passa a ser questionado como resultado da mudança do enfoque de "Estado-agressor para Estado-protetor". E a terceira, seria a de natureza filosófica, a que vivenciamos neste momento desde a década de 70, na qual há uma desagregação dos princípios de organização social como fracasso da antiga concepção de direitos sociais.

Ainda com Rosanvallon (1998), a crise está intimamente ligada às novas funções que estão sendo exigidas do Estado-providência, como a exigência de novos caminhos para a inserção de excluídos na sociedade. Esta crise leva a uma retomada da questão dos direitos que surgiram no século XVIII e que foi difundida sob uma perspectiva liberal-individualista, obrigando a se reformular os moldes do "contrato social" no contexto europeu e a reconsiderar as diversidades culturais e os traumas pós-colonialistas no contexto americano. O crescimento do desemprego, do individualismo e da falta de solidariedade social são os fatores que irão demandar um profundo questionamento da própria concepção de direitos sociais, do que seria justo e equitativo como prática fundamentalmente democrática.

\footnotetext{
a sua principal causa seria necessário entregar à cidade o direito de punir possíveis transgressores de suas normas, enquanto o resto da população se compromete a não ajudar o punido. A espada da justiça, entregue ao governo da cidade, portanto, é direito legítimo de legislar e punir os cidadãos que ameacem de alguma forma as suas leis.

${ }^{3}$ De uma perspectiva histórica e moral, Rousseau defende não a natureza humana individual, mas sim o homem atuando na forma Sociedade-Estado. No estado de natureza, os homens não são agressivos, pois possuem tudo o que a natureza tem para oferecer. A lei natural, consagrada na natureza humana, não permite que o homem leve a cabo o sacrifício de vidas humanas, excetuando-se quando em detrimento da própria, portanto, cria um homem que em seu estado natural estaria aquém da idéia maniqueísta de bem e mal. Seu instinto natural residiria apenas no amor de si. O amor-próprio conteria toda a perversão humana futura, mas apenas brotaria do convívio social. A ânsia de destacar-se dos outros é interpretada como criação de diferenciação e isso leva ao distanciamento de nós mesmos. Cf. "Discurso sobre a desigualdade" e "Discurso sobre as ciências e as artes" Coleção Os pensadores. Ed. Abril.

${ }^{4}$ Para uma análise crítica das teorias sociais e morais da modernidade Cf. Freitag, Barbara in "O itinerário de Antígona: a questão da moralidade, 1992”.
} 
A obrigação moral a que fica sujeito o Estado implica uma redefinição dos termos "contratuais" como medida eficaz para associar direitos com contrapartidas positivas, isto é, haveria uma demanda por uma socialização da responsabilidade individual como tarefa política, na qual o Estado passa a ter como função restabelecer e reforçar o vínculo social, tornando-o visível. Seguindo a mesma linha, Bernardo Sorj $(2004 ; 26)$ discorre sobre a forma como a globalização passou a afetar a vida nas sociedades e como a oposição original "trabalhador/povo x capitalismo/elite" foi substituída por novas categorias fragmentadas e fragmentadoras da vida social que colocam em xeque o "bem comum" através da fragmentação simbólica, que é resultado do individualismo triunfante, da desigualdade social e do rompimento dos laços de solidariedade. O enfoque dos direitos humanos passa a ser a língua da globalização e a questão da cidadania se transforma em questão de justiça, no sentido Rawlsiano.

Ao analisar a cidadania de forma plural, Boaventura de Souza Santos (1995), aponta que a perspectiva da cidadania se deu na modernidade sob diversos prismas. Do lado da teoria política liberal, o princípio do mercado cresceu sobre o princípio do Estado e ambos atrofiaram o princípio da comunidade. Das diversas teorias políticas de cunho liberal, um ponto central se desenvolveu em torno do ideal de indivíduo autônomo e livre, compatibilizado com o Estado como protetor e garantidor deste ideal. Paralelamente ao desenvolvimento capitalista e as consequências urbanas e sociais que advém deste fenômeno, a partir dos anos 60 há um fervilhamento de correntes teóricas sociais e políticas que visam entender as novas configurações sociais e econômicas que vêm se instalando no mundo. Muitas destas teorias exerceram forte influência no pensamento social brasileiro na medida em que buscam novas formas equitativas de distribuição econômica e social.

Um ponto em comum com as variadas correntes teóricas é a ênfase na defesa de uma sociedade democrática liberal. O debate teórico se volta tanto para a lógica liberal da liberdade - no sentido dos Direitos Humanos sob viés republicano quanto à lógica democrática da igualdade no sentido da soberania popular ${ }^{5}$. Embora detenhamos verticalmente, os direitos sociais garantidos pela Constituição, horizontalmente possuímos ${ }^{6}$ uma "solidariedade de Banfield", isto é, não alargamos para fora das nossas relações mais próximas os direitos que consideramos válidos para nós.

Para entendermos alguns aspectos desta contradição, torna-se imprescindível analisar um pouco da construção da cidadania no Brasil e como a sociologia política vem trazendo para

\footnotetext{
${ }^{5}$ Para ver a convergência da concepção republicana à liberal num logica democrática, Cf. Gisele Cittadino: "Pluralismo, Direito e justiça distributiva: elementos da filosofia constitucional contemporânea".

${ }^{6}$ Não há aqui uma evocação essencialista de uma cultura brasileira. Aponto apenas que esta "solidariedade" está presente em nossa sociedade e não que ela a defina.
} 
esta discussão vários teóricos da justiça social para que ampliemos cada vez mais a realização de direitos no Brasil. A construção da democracia no ocidente, desde a antiguidade até a modernidade vem sendo reiteradamente renovada por novos mecanismos de inclusão de parcelas significativas da população que até então não eram beneficiadas. Da democracia ateniense que congregava apenas os cidadãos livres ${ }^{7}$ à democracia francesa construída sob as bases dos princípios da liberdade e da igualdade formais, busca-se hoje a ampliação das condições de participação para a real efetivação dos direitos para todos integrantes da sociedade.

Marshall (1967; 61-64) problematizou, centrado na Inglaterra dos anos 50, o contraste entre o capitalismo e a desigualdade defendendo que a cidadania seria uma reivindicação legítima para o indivíduo ser admitido como participante dentro de determinada herança social, o que por sua vez significaria a aceitação como membro completo de determinada sociedade. Para o autor, a desigualdade no sistema de classes seria mitigada pelo status de cidadania, quando a igualdade pode ser reconhecida. No universo deste conceito, ele aponta três diferenciações: cidadania civil que se traduz na liberdade de ir e vir, no direito à justiça, nos direitos individuais de uma maneira geral; cidadania política, como participação no exercício do poder político e cidadania social, que implica desde o direito a um patamar mínimo de bemestar econômico, à segurança de participar por completo da herança social de acordo com os padrões que prevalecem na sociedade.

Desta forma, segundo Sorj (2000), o conceito de cidadania social no capitalismo visa assegurar a igualdade entre os cidadãos na esfera legal e política, visto que o sistema econômico se fundaria na desigualdade de acesso à propriedade. Os direitos políticos e sociais permitiriam, portanto, compensar a defasagem entre os dois sistemas, garantindo pelo menos a igualdade de chances. A trajetória da construção e o desenvolvimento da cidadania na Europa desde o século XVIII como aponta Marshall - relacionado aos deveres introjetados nos cidadãos como participantes na sociedade - até os dias de hoje, possui variados contornos que se mantêm ou se modificam dadas as circunstâncias históricas. No período iluminista britânico, os direitos estavam marcados pela classe que, por conseguinte atribuíam o status de direitos políticos e de cidadania àqueles que nela estavam inseridos. Apenas a partir do século XIX, as noções de igualdade e de liberdade começam a tomar forma conjuntamente ao Estado nacional, unificando, posteriormente, no século XX, direitos sociais a direitos políticos enriquecendo, assim, o status ${ }^{8}$ universal da cidadania.

\footnotetext{
${ }^{7} \mathrm{O}$ demos ateniense era de uma elite minoritária da qual a maior parte da população de escravos estava totalmente excluída, assim como as mulheres. Cf. Finley, M. in "Democracia antiga e moderna".
} 
Seguindo a linha de Marshall e avançando na sua concepção, Brian Turner irá analisar a política de status na sociedade contemporânea de forma a demonstrar que o ambiente político da sociedade industrial que refletia as concepções de individualismo e igualitarismo, concebia a vida social como um jogo competitivo na qual todos os participantes teriam partido do grau zero na corrida econômica de sobrevivência. A política do status emerge deste ponto, no momento em que determinados grupos que não estão em situação igual na "partida" começam a requerer a intervenção do governo como forma de compensação para sua desigualdade factual.

Os direitos de cidadania no contexto europeu estavam relacionados à igualdade perante a lei. Embora esta igualdade tenha se desenvolvido paralelamente com o fenômeno da desigualdade social e econômica, apesar de garantida a liberdade individual e os direitos civis trabalhistas, a presunção da autonomia individual destruiu qualquer possibilidade de proteção do tipo igualitário, deixando as classes menos favorecidas à mercê das intempéries econômicas (Bendix;1996). A construção do laissez-faire não buscava igualdade de condições, mas liberdade de se construir economicamente como cidadão, ou seja, apenas autonomia para adentrar a luta econômica, o que de certa forma impedia uma possível reclamação por qualquer proteção legal do Estado ou benefício social neste sentido.

Sob a perspectiva histórico-política brasileira já foi mostrado que sob a ótica econômica, durante toda a moldagem da Primeira República eram protegidos os direitos de propriedade, e em contrapartida, mantinham-se os privilégios de uma elite que acreditava estar moldando o país e assim se perpetuava o status quo da diferenciação social (Santos;1994). Nestes termos, tivemos liberdades básicas associadas à sociedade de mercado e não tivemos justiça social aliada à liberdade política. Dado isso, torna-se importante voltar um pouco na construção histórica da desigualdade brasileira, o que remonta à colonização, para que se possa acompanhar a diferenciação social que foi estabelecida e perpetuada desde então.

A partir da relação entre as três raças no Brasil, Gilberto Freyre (2000) mostrou que o hibridismo foi a forma eficaz da relação do português com o colonizado, na qual ordem e autoridade da tradição patriarcal combinavam com relações de sadismo sexualizadas, amalgamando parentesco e dominação. Desta forma, o negro escravo tornou-se o parente pobre das famílias europeias no Brasil. Características observadas pelo europeu sobre o escravo passaram a deter uma conotação negativa na medida em que se tornaram parte da natureza do africano quando não estavam de acordo com os anseios do europeu. Se ele não quisesse trabalhar, era indolente; se agisse de determinada forma, era classificado de acordo com os valores ocidentais e estas características personalizadas tornavam-se sua "essência," o que sempre possuía um caráter negativo. 
Este antagonismo se tornou mais claro na medida em que surgiram abordagens científicas neodarwinianas sociais para corroborar com tal classificação social. O sistema político que se forma após o período escravocrata e advento da república manteve os mesmos traços da perversidade do sistema anterior, isto é, a diferenciação e a estratificação social que persistiram o que dificultou ainda mais a reparação das novas injustiças tendo como base valores universalistas que não chegavam aqui (Schwarz; 2008). Tanto as classes inferiores como os comerciantes, senhores de terra e governantes refletiam a degradação do sistema, mas cambiavam de um lado a outro de acordo com seus interesses econômicos. Os valores franceses de igualdade, liberdade e fraternidade, embora tenham embasado a construção da República no Brasil por um grupo minoritário ligado à maçonaria ${ }^{9}$ foram adaptados e harmonizados com o novo sistema político republicano de forma que não o maculassem no seu todo. Assim, segundo Schwarz, as ideias liberais europeias que aterrissaram aqui professavam o escândalo no nosso sistema agrário e do nosso raciocínio econômico burguês, isto é, a supremacia do lucro sobre os corolários sociais. A dissonância entre o que se considerava moderno e o que se efetivava na realidade também foi reafirmada, segundo Schwarz, por Marx, ao expor o antagonismo da luta de classes na Europa e os valores humanos defendidos pela Revolução francesa. Ainda segundo Schwarz, no Brasil, as transformações sociais foram superficiais, não podiam ser praticadas, mas o ideal liberal também não poderia ser descartado, sendo posto e reposto de acordo com o nexo colonial, isto é, sempre em sentido impróprio.

A perspectiva analítica de classes foi maciçamente estudada no Brasil e Caio Prado (1994) foi um dos primeiros a partir da análise da cultura portuguesa, seus usos, crenças e valores que serviram de base para a formação do Brasil como sociedade e como nação. Toda sociedade teria se fundado em dois instintos primitivos característicos do homem português, o econômico e o sexual. A partir do primeiro instinto se desenvolve o trabalho, a escravidão e toda a segregação social que decorre daí. A partir do segundo, surge a relação afetiva e cruel de discriminação e personalismo, fundada na família e na dissolução dos costumes. Estas dicotomias são apresentadas pelo autor como a incongruência de um sistema que, por ser baseado prioritariamente no interesse econômico, não permitiu a mínima possibilidade de ascensão de um critério universalizante de justiça.

\footnotetext{
${ }^{9}$ Segundo Maria Beatriz Nizza, os valores da liberdade, fraternidade e igualdade para os portugueses que aqui viviam eram entendidos como valores franceses e associados a um caráter revolucionário, possuindo uma conotação pejorativa muito forte. Pensar nestes valores significava para eles ser ateu, ter uma concepção materialista e anti-católica. Cf. "Cultura e sociedade no Rio de Janeiro - 1808-1821.” p.116
} 
Esta dificuldade social também é interpretada por Sergio Buarque de Holanda como a forma legítima de lidarmos com o conflito e a diferenciação ${ }^{10}$. O sentimento incapacitante de se buscar direitos é descrita por Buarque de Holanda em "Raízes do Brasil" como um mal de origem na trajetória dos conquistadores portugueses. A colonização teria formas de exploração e conquista que resultariam em relações patrimoniais, amparadas no favor e no castigo, sentimentos estes característicos das relações familiares que se tornariam as peças-chave para compreender nossa atitude cívica.

Sob a perspectiva histórica, Holanda demonstra que na estrutura política da sociedade, a construção da nação e com o advento de certo desenvolvimento industrial no século XIX, a herança rural predominava e resistia à construção das cidades urbanizadas - estas dependentes da colônia e dos fazendeiros escravocratas - de forma que as transformações sociais teriam se dado de forma bastante superficial no intuito de manter o passado tradicional do domínio colonial. (Holanda; 1981) Disso se infere que a noção de cidadania se realizaria no Brasil de forma inversa, na qual os princípios basilares de igualdade e liberdade seriam traduzidos como cordialidade, uma forma cruel de hierarquizar e diferenciar quem poderá e quem não poderá usufruir direitos. Nas palavras de Holanda $(1981 ; 107)$ :

(...) a amizade, desde que abandona o âmbito circunscrito pelos sentimentos privados ou íntimos, passa a ser, quando muito, benevolência, posto que a imprecisão vocabular admita maior extensão do conceito. Assim como a inimizade, sendo pública ou política, não cordial, se chamará mais precisamente hostilidade. (...)

A análise histórica destes processos torna-se de extrema importância para que possamos compreender as bases que fundamentam a contínua disparidade socioeconômica que vivemos. Numa perspectiva culturalista, Roberto DaMatta (1993), vê que o sentido de hierarquia no Brasil foi fundado no sistema colonial, na forma de pirâmide em que o comércio era a base social, as leis seriam os meios de legitimação do poder e o Rei a cabeça guia da colonização e exploração do território. Neste cenário, cada um teria o seu lugar demarcado plena e anteriormente a qualquer função e cada categoria possuiria direitos e punições específicas, o que reafirmaria ainda mais o caráter "desigualitário" da sociedade brasileira.

\footnotetext{
${ }^{10}$ Cf. Holanda, Sergio Buarque "Raízes do Brasil" e "Visão do paraíso: Os motivos edênicos no Descobrimento e colonização do Brasil." Este último tem o intuito de traçar o mito de um Brasil edênico. Para isso, Buarque analisa o precoce desencantamento do português com o éden terreal brasileiro em comparação com os conquistadores espanhóis, que veriam no Brasil um território idealizado. A imaginação européia medieval religiosa detinha antigas superstições mitológicas, como monstros e seres fantásticos que seriam obstáculos para a vida paradisíaca na Terra. A isso, se somavam tradições orais e mitos originários da Europa, como por exemplo, a lenda das pegadas, das prédicas e dos milagres de São Tomé nas Índias que para os portugueses seriam o indício da sacralidade do território brasileiro.
} 
Ainda com DaMatta, neste sistema, a escravidão do negro era naturalmente um complemento ao domínio branco, e as relações de intimidade que daí decorreram, asseguravam ainda mais a superioridade branca como grupo dominante, mantendo cada um no seu lugar e desenvolvendo o sentimento de favor como um valor associado ao sistema hierárquico natural.

A discriminação, assim, só ocorreria quando algum elemento estivesse fora do círculo hierárquico, ou seja, quando alguém não está integrado dentro deste sistema de relações originalmente legitimado. Como ressalta o autor $(1993 ; 237)$

No sistema social brasileiro, então, a lei universalizante e igualitária é utilizada frequentemente para servir como elemento fundamental de sujeição e diferenciação política e social. Em outras palavras, as leis só se aplicam aos indivíduos e nunca às pessoas; ou ainda melhor, receber a letra fria e dura da lei é tornar-se imediatamente indivíduo.

Assim, no aspecto político, consequentemente, a conotação de indivíduo sempre seria negativa, visto a construção dos valores morais no Brasil poder ser entendida como resultado da interação entre os diversos tipos humanos e a estrutura socioeconômica que foram desenvolvidas desde o período colonial. Os articuladores políticos eram os mesmos que legitimavam a ordem hierárquica e discriminatória, ao mesmo tempo em que concediam favores, tornando as relações pessoais requisitos para qualquer tipo de mobilidade social.

Como resultado da colonização e com o processo de libertação dos escravos a partir do fim do século XIX, vemos o acúmulo de uma massa de desempregados relegados aos mais miseráveis salários e condições de vida. Aos ex-escravos não foram fornecidos meios para sobrevivência, saúde, educação, moradia, apenas o mesmo trabalho - escravo - com péssimos salários. A população negra, portanto, teve que arcar sozinha com o ônus da libertação e tentar sobreviver pelos seus próprios meios, sem galgar nenhuma ascensão social, apenas individual e pessoal, como favor ou privilégio. Para Maria Sylvia de Carvalho Franco (1997; 54) a pobreza de recursos e a busca nômade por condições de sobrevivência não tornou possível a cristalização de valores pétreos que pudessem ser passados através das gerações. Como aponta Caio Prado, o sistema escravocrata não produziu superestrutura e a pobreza cultural favoreceu a pouca disposição ao trabalho - que no campo era considerado em grande escala como desperdício devido às intempéries da natureza - e poucas normas de regulamentação trabalhista. Ser senhor de terra era ter poder e autoridade e status.

A dificuldade de se analisar a sociedade brasileira como um todo se justifica na imensa variedade regional e cultural de Estado para Estado. Entretanto, um dos vieses de análise da sociedade brasileira se dá através das imigrações para a cidade como consequência da impossibilidade de sobrevivência no campo. Este aspecto é de valiosa importância, pois visa 
demonstrar a dificuldade do ex-camponês na luta por melhores condições de vida que se conjuga aqui no Rio de Janeiro a mesma luta do homem livre e pobre.

A independência financeira era aspirada como ideal de obtenção de justiça e na falta desta, a violência decorrente do conflito se tornaria a única saída possível para a manutenção de um mínimo de integridade pessoal. O imigrante, portanto, sai em busca de sua sobrevivência, e se depara com uma nova cultura na cidade que não reflete seus anseios nem contribui efetivamente para a melhoria de sua vida. Em seu livro, Maria Sylvia parte dos processos-crime na região do Vale do Paraíba em São Paulo, procurando analisar os comportamentos que refletem o modo de vida típico das populações rurais brasileiras: poder paterno, respeito filial, religiosidade, relação com a natureza e vínculos familiares. Estes aspectos culturais são contrastantes com a irrupção de uma personalidade violenta e individualista que se desenvolve no chamado homem livre, ou ex-escravo e sua relação com o novo modo de produção capitalista, assim como a significação desta relação na vida social desses indivíduos. Nesta cultura, considerada pobre, pois que com poucas opções de vida, busca-se somente a satisfação dos mínimos vitais.

No entanto, seguindo ainda a autora, a hierarquia social e a individualidade como expressões culturais são os instrumentos de interpretação da comunidade, no que diz respeito tanto às relações de trabalho quanto na memória comum, na amizade, na vida coletiva, e são estes instrumentos que impossibilitarão o surgimento de um aprofundamento das relações sociais como organização social. Como parâmetro de obtenção de justiça, status e liberdade, a figura do proprietário de terras vai percorrer todo o ideário social brasileiro desde as camadas mais pobres até a ascendente burguesia. A maneira pelas quais as relações de poder se desenvolveram com o enfoque no poder local no início do século XX retrata um sistema político que vai desde o coronel até o presidente da República. O coronelismo seria, assim, um sistema político baseado em barganhas entre o governo e o poder local dos coronéis.

O governo estadual garantiria o poder do coronel sobre seus dependentes cedendo-lhe o controle dos cargos públicos e o coronel fornece seu apoio ao governo através de votos. Este esquema político só teria se tornado possível devido a uma estrutura econômica e social inadequada. A forma peculiar com que se desenvolveu o poder privado como regime político só é compreensível através da análise da estrutura agrária massificadora da vida no latifúndio, na qual pessoas em condições subumanas "arrastam a existência" num sistema rural decadente baseado na pobreza ignorante do trabalhador da roça. A noção de coronelismo teria como referência a existência local de estruturas oligárquicas e personalizadas de poder. $\mathrm{O}$ mandão seria aquele que, em função do controle de algum recurso estratégico, em geral a posse da terra, exerceria sobre a população um domínio pessoal que a impediria de ter livre acesso ao mercado 
e à sociedade política. $\mathrm{O}$ mandonismo não seria, contudo, um sistema, mas uma forte característica da política tradicional que existe desde o início da colonização e que irá desaparecer à medida que os direitos civis e políticos passam a alcançar todos os cidadãos. Como complemento, Florestan Fernandes (2006) desenvolveu a tese de que os estamentos médios no século XIX não cumpriram sua missão histórica de fazer a ruptura com o legado colonial e a forma tradicional de práticas sociais, visto que, como vimos com Sergio Buarque, houve uma superposição do público pelos interesses privados que percorreu toda a nossa história.

Desta forma, podemos dizer que a cultura política e os acordos e desacordos sociais no Brasil provenientes dos arranjos econômicos e políticos no Brasil desde a colonização propiciaram e fundamentaram todo um ideário social específico que reinterpretava e reinterpretava as diversas influências que sofremos vindas da Europa e do resto do mundo e a partir disso adaptamos aquelas para a nossa própria estrutura social. Disso temos como resultado um apanhado de práticas sociais contraditórias que ensejam sempre a manutenção de uma relação de domínio e exclusão social. Estas poucas análises da formação política brasileira visaram retratar a dificuldade de se estabelecer um patamar mínimo de justiça universalizante que se realize nas práticas sociais. $\mathrm{O}$ autoritarismo, a hierarquia e o conservadorismo impossibilitaram a mudança na estrutura desigual da sociedade brasileira, tornando banal uma situação de extrema injustiça social.

Como complemento, os ideais de igualdade foram mitigados por práticas católicas assistencialistas, colaborando para a aceitação geral desta situação social e reafirmando a caridade como único meio na relação com os mais pobres. A partir dos anos 80, o Brasil adentra uma nova fase de integração econômica mundial e com ela emergem milhares de pessoas “inimpregáveis". Surgem com o novo contexto capitalista, os que involuntariamente ${ }^{11}$ estão desvinculados do mundo do trabalho, como catadores de lata, de papelão, camelôs, dentre outros que por trabalharem em biscates, sem salário fixo, permanecem na rua por falta de opção. Seu mundo se restringe às ruas e seu trabalho se dá nas ruas. Estas pessoas obtêm apenas o necessário à subsistência imediata: comida.

Como mostra Vera Telles (2001; 59), é em uma definição de justiça e de igualdade que se constrói a figura da pobreza no Brasil, pois, a noção de justiça teria se tornado desfigurada de forma a manter o caráter da pobreza como natural, relacionando hierarquia natural ou religiosa à mundanidade. A privação de direitos, para Vera Telles, se construiu simbolicamente, relacionando as diferenças sociais como compatíveis com um sistema de justiça, no qual cabem as discriminações. Esta aparente contradição transforma o ilegítimo em legítimo, o injusto em 
justo. Algumas destas categorias de oposição se transformaram em códigos culturais e se inseriram homogeneamente nas tradições, experiências e no imaginário do cotidiano social. Segundo a autora, é na articulação das leis, cultura e tradições que percebemos os aspectos mais diferenciadores e autoritários da sociedade brasileira. Assim, as diferenças sociais são transformadas em hierarquias de forma legitimada e a pobreza passa a ser associada à desordem moral.

Como resultado dessas práticas sociais a efetivação de direitos se torna inócua” visto que há um "cultivo de valores distintos diante de situações idênticas" e a figura do outro aquele que não faz parte do todo social - é sempre difusa e ameaçadora e o acesso à cidadania, como consequência, é dificultado e inviabilizado, num mundo social em que alguns são mais cidadãos que outros, e os direitos mais básicos como acesso à habitação, alimentação ou trabalho são escassos. Assim, a imensa desigualdade social que convivemos todos os dias, como afirma Cristovam Buarque (1996), gera uma situação de dessemelhança, caracterizada pela ruptura dos laços de solidariedade e de pertencimento à espécie, a mesma espécie, humana. Assim, quando o Estado não proporciona mecanismos de proteção sociais amplos e universais, a exclusão se manifesta não apenas na dimensão social, mas também na esfera da sobrevivência.

A construção do conceito de cidadania pode ser entendida assim, de acordo com dois vieses: Um com uma acepção republicana que remonta à antiguidade e às virtudes de participação na comunidade. E o outro como consumidor de direitos a partir da era moderna, tendo a base filosófica dos contratualistas como precursores da idéia. A partir daí, a cidadania pode ser estudada sob o viés da inclusão e da exclusão, isto é, de quem participa ou não, ou de quem têm direitos ou não. A inclusão da cidadania pelo Estado requereria uma dimensão vertical, do Estado para o indivíduo, enquanto a cidadania republicana poderia ser interpretada hoje como um reconhecimento horizontal de cidadania, isto é, ao reconhecimento entre pessoas como iguais detentores de direitos (Elisa Reis;1988). Temos, portanto, uma dupla produção da pobreza: os novos pobres, isto é, aqueles que estão à margem do sistema econômico e possuem um patamar mínimo de sobrevivência, isto é, pertencem a uma linha de pobreza conceitual muitas vezes definida como relativa ${ }^{12}$; e aqueles que estão fora do sistema, isto é, desfiliados ${ }^{13}$, desinseridos ${ }^{14}$ ou miseráveis, definidos como dentro de um patamar de extrema pobreza, sem grupo específico e de difícil especificação.

\footnotetext{
${ }^{12}$ Sobre a diferença entre pobreza extrema e pobreza relativa, ver. Sonia Rocha "Pobreza no Brasil: afinal do que se trata"? Ed. FGV, 2003.

${ }^{13}$ A desfiliação significa o conceito de ruptura do pertencimento de vínculo sócia. As condições sociais de recursos escassos fragilizariam o tecido relacional dos indivíduos a sociedade. Cf. Robert Castel "Desigualdade e a questão social.” Ed. EDUC, São Paulo, 2007

${ }^{14}$ A desinserção questiona a existência dos indivíduos enquanto seres sociais. É o inverso da integração, na qual o autor busca relacionar o aspecto simbólico dos fenômenos de exclusão, pois seria o sistema de valores de uma
} 
Diante do acima exposto, a cidadania, pode ser relacionada diretamente à qualidade de vida das pessoas através da efetivação de seus direitos. As vulnerabilidades sócio-econômicas traduzem um abismo que separa quem é cidadão de quem não é, hierarquizando pessoas de acordo com a fruição de seus direitos e estes podem ser entendidos como privilégios, uma vez que não são universalizados. Assim, as relações pessoais nos diversos segmentos da sociedade traduzem a eterna diferenciação hierárquica que insistimos em reiterar. A ligação entre um "superior" e um "inferior" se dá através da amizade e da relação de intimidade que une os indivíduos e os transformam em "pessoas" ou da cordialidade de que nos falava Holanda (1981). As práticas sociais diárias dos brasileiros demonstram a dificuldade de realização da igualdade levando à reafirmação do comportamento personalista.

Este é um grande paradoxo social que define e nivela a capacidade de exercício da cidadania. Como consequência da análise da evolução histórica brasileira e da forma como se circunstanciaram algumas das contradições sociais, emerge uma indiferença generalizada que perpassa toda a sociedade e que decompõe aos poucos o que poderia restar de apreciação moral e equilíbrio social.

No Brasil, não enxergamos a existência de classes, preferimos atribuir ao indivíduo uma ideologia do mérito, ficando assim à responsabilidade individual toda a culpa pelo insucesso econômico. A desigualdade, desta maneira é mascarada. A importância desta discussão reside no fato de que é importante verificar novas formas de análise das desigualdades no Brasil, que conjugue tanto as desigualdades socioeconômicas como as dimensões simbólicas que reafirmam aquelas. Como bem desenvolve José Murilo de Carvalho (2010) a relação entre o indivíduo e o Estado ou entre a sociedade e o Estado até o século XIX se concretizava de forma maniqueísta, na qual o Estado ativo era considerado paternalista ou um mal necessário e a sociedade era entendida como vítima ou como passiva. Esta relação, portanto, inviabilizava qualquer noção de cidadania. Com a Abolição e o contingente de desempregados lançados à rede de práticas punitivas de vagabundagem e vadiagem, agrava-se a problemática do imaginário social relacionada ao capoeira ou aos possíveis gatunos ou desocupados (idem; p.16-18).

Ressaltando a inter-relação econômica e política que perpassava a estrutura social, Simon Schwartzman (2004) ressalta que como a sociedade brasileira no final do século XIX ainda era constituída de uma pequena elite branca, um grande número de escravos, imigrantes pobres europeus e uma economia escravista decadente, o que resulta deste processo histórico é a conjugação da nova configuração econômica mundial na qual estamos inseridos com uma

sociedade que define os que estão "fora da norma" como não tendo valor ou utilidade social. Cf. Vincent de Gaulejac "La lutte de places", Ed. Gallimard, 2009. 
economia de mercado globalizante que prolonga a desigualdade social com um número crescente de pobres e não cumpre a promessa de modernização e mobilidade social. A pobreza se torna aliada do imaginário do crime, quando não está de fato entrelaçada a ele, e o escasso acesso aos bens disponíveis, tais como saúde, segurança e educação são sucateados pelo Estado. A concepção de Justiça social de David Harvey (1980) ajuda a entender como o espaço urbano de acordo com um conteúdo estritamente normativo que deve ser discutido à luz das considerações filosóficas de análise. Para isso, a justiça deve ser pensada como um princípio para uma aplicação particular numa situação de conflitos que surgem diretamente da necessidade de cooperação social. Assim, justiça social demanda uma compreensão de um processo no qual o significado ou os conteúdos destes termos devam estar relacionados a um processo de construção do espaço social e suas divisões. A forma como o desenvolvimento urbanista se espacializa, criando centro e periferia, ou seja, fronteiras e divisas concretas geram como consequência, significações simbólicas também fronteiriças, na medida em que dividem o espaço e a representação que se tem dele.

O Rio de Janeiro, em sua dimensão espacial e política, se torna "escassa", (Carvalho;1995) na medida em que vira objeto de disputa hobbesiana para comportar cidadania para todos. A falta de desenvolvimento da periferia e a crescente favelização do espaço urbano não é apenas o resultado da imensa disparidade social, mas causadora de uma rede de simbolismos aliados a esta desigualdade. Quando a cidade se torna objeto da apropriação privatista onde residem a desconfiança e o ressentimento sociais, o padrão de exclusão aumenta e a cidadania se torna residual. Se pudermos afirmar que há uma antinomia de valores na abordagem dos direitos humanos, na qual ao mesmo tempo em que o Estado vela pela liberdade individual e esta se assegura através dos valores individualistas, também vela pela igualdade entre os cidadãos através do acesso dos mais desfavorecidos a condições mínimas de integração na vida social, o que reflete valores supra- individuais solidários (Sorj;2000). Para compreender este argumento, Jessé Souza $(2003 ; 176)$ aponta que a ideologia espontânea do capitalismo tardio reduziu a complexidade social, tornando incapazes os membros da sociedade de perceber o sentido cotidiano das desigualdades, já naturalizadas e tornadas partes do cenário do dia-adia, como foi mostrado há pouco.

Como aponta Angela Paiva (2003), "quando a cidadania é conseguida de cima, termina por gerar uma cidadania predominantemente passiva, visto que estariam ausentes os traços universalistas da concepção de direitos individuais. Já Elisa Reis (1998), dá ênfase ao aspecto político da falta de integração social, na qual a pobreza extrema em combinação com a cultura da desigualdade gera uma espécie de identidade social restritiva, alienada da esfera política, na qual o conceito de cidadania existe em descrédito, na medida em que algumas camadas da 
sociedade desfrutam da cidadania como status de privilégio. A falta de distribuição de bens sociais para a satisfação de necessidades básicas gera uma massa de "pobres" ou "indigentes" que são vistos como perigosos e geradores de violência. A responsabilidade estatal é vista como a forma de proteger as elites dos pobres perigosos que seriam perigosos por serem invejosos da riqueza das elites. Este ponto, defendido por Elisa Reis, nos mostra como a forma de culpabilizar o Estado também é a forma de se eximir de qualquer responsabilidade assim como também transforma a desigualdade em natural, para que se mantenha o status quo do sistema estrutural existente.

Tentei neste artigo mostrar um pequeno panorama da diversidade conceitual e teórica de análise das questões concernentes à justiça social e sua influência nas relações sociais no Brasil em torno do tema da cidadania. Os valores, a cultura política, e os costumes relacionamse intimamente com a estrutura socioeconômica e desta mistura resultam representações sociais que se manifestam muitas vezes inconscientes no dia-a-dia. Isso também aparece nitidamente através do discurso e da opinião pública, seja no "boca a boca", seja no gestual do cotidiano.

\section{BIBLIOGRAFIA}

Bendix, Reinhard: Construção Nacional e cidadania: estudos de nossa ordem social em mudança. Ed. Edusp, 1996.

Benhabib,Seyla: The rights of others: aliens,residents and citizens. Cambridge University Press, 2004.

Caliman, Geraldo: Paradigmas da exclusão social. Ed.Universa ; UNESCO, 2008.

Carvalho, José Murilo de: Cidadania no Brasil: o longo caminho. Editora civilização Brasileira, Rio de Janeiro, 2002.

Os Bestializados: O Rio de Janeiro e a república que não foi. Editora Companhia das letras, São Paulo, 2010.

Carvalho, Maria Alice Rezende: Quatro vezes cidade. Editora Sette Letras, Rio de Janeiro, 1994.

Castel, Robert: Desigualdade e a questão social. Ed. EDUC, São Paulo, 2007

Damatta, Roberto: : A casa e a rua: espaço, cidadania, mulher e morte no Brasil. Editora Rocco, Rio de Janeiro, 1997a.

Franco: Maria Sylvia de carvalho: Homens livres na ordem escravocrata. Ed. UNESP, 1997

Gouth, Jamie et alii. Excluding societies. Routledge, London and New York, 2006

Holanda, Sergio Buarque de: Raízes do Brasil. Editora José Olympio, Rio de Janeiro, 1936.

Lima, Mario Helio Trindade: Exclusão social: representações sociais da pobreza urbana no Brasil. Ed.UFES Espírito Santos, 2005.

Marshall, Thomas: Cidadania, classe social e status. Zahar editores, Rio de Janeiro, 1967. 
Paiva, Angela Randolpho: A difícil equação entre modernidade e desigualdade. In Interseções 6, 2003.

Reis, Elisa: Processos e escolhas: estudos de sociologia política, Ed. Contracapa, Rio de Janeiro, 1998.

Rosanvallon, Pierre: A nova questão social: repensando o Estado-providência. Brasília: Instituto Theotonio Vilela, 1998.

Schwarz, Roberto: Ao vencedor as batatas: forma literária e processo social nos inícios do romance brasileiro. Ed. 34, 2008.

Sen, Amartya: Desigualdade reexaminada. Ed. Record, 2001.

Sorj, Bernardo: A nova sociedade brasileira. Ed. Jorge Zahar, Rio de Janeiro, 2000.

Souza, Jessé: A construção social da subcidadania: para uma sociologia política da modernidade periférica. Editora UFMG, Rio de Janeiro, 2006.

: A ralé brasileira; quem são e como vivem. Ed. UFMG, 2009.

Schwartzman, Simon: Pobreza, exclusão social e modernidade: uma introdução ao mundo contemporâneo. Ed. Augurius, 2004.

Taylor, Charles: As fontes do self: a construção da identidade moderna. Edições Loyola, São Paulo, 1989.

"What's human agency?" in Human agency and language" Philosophical papers 1. Cambridge University Press.

Telles, Vera da Silva: Direitos sociais: Afinal do que se trata? Editora UFMG, Belo Horizonte, 2006. 